\title{
Compreensão e utilização de textos de divulgação científica por professores de Química das escolas públicas da região de Blumenau/SC
}

\author{
Understanding and use of popularization of science texts by chemistry \\ teachers of publics schools of Blumenau/SC region
}

\section{Comprensión y uso de textos de divulgación científica por profesores de Química de escuelas públicas de la región de Blumenau/SC}

Raisa Krazewsky (rkrazewsky@gmail.com)

Universidade Federal de Santa Catarina

Graziela Piccoli Richetti (graziela.richetti@ufsc.br)

Universidade Federal de Santa Catarina

Resumo: A presente pesquisa teve como objetivo investigar o entendimento dos professores entrevistados sobre a utilização de textos de divulgação científica nas aulas de Química, bem como identificar se e como ocorre o uso desses textos em sala de aula. O trabalho justifica-se pela necessidade de formar estudantes alfabetizados cientificamente, capazes de olhar o mundo criticamente e provocar-lhe mudanças com posicionamentos fundamentados e responsáveis, tendo como base que o domínio do conhecimento científico e a compreensão da natureza da Ciência são necessários para entender como os conhecimentos científicos implicam nas diversas esferas da sociedade. Para isso, foram aplicados questionários e realizadas entrevistas com professores de Química atuantes na rede pública da região de Blumenau/SC, cujas respostas foram categorizadas e submetidas à Análise de Conteúdo. Verificou-se que os textos estão em sala de aula, mas não são amplamente explorados, indicando uma necessidade de complementar a formação dos docentes.

Palavras-chave: textos de Divulgação Científica; instrumentos de Ensino de Química; formação de professores.

Abstract: The present research aimed to investigate the understanding of the interviewed teachers about the use of popular science texts in Chemistry classes, as well as to identify if and how the use of these texts occurs in the classroom. The work is justified by the need of forming scientifically literate students, able to look at the world critically and bring about changes with reasoned and responsible positions, based on the fact that the domain of scientific knowledge and the understanding of the nature of Science are necessary to understand how scientific knowledge implies in the various spheres of society. For this, questionnaires were applied and interviews were carried out with Chemistry teachers working in the public network in the region of Blumenau/SC, whose answers were categorized and subjected to Content Analysis. It was found that

Recebido em: $17 / 02 / 2021$

Aceite em: $31 / 08 / 2021$ 
the texts are in the classroom, but are not widely explored, indicating a need to complement the formation of teachers.

Keywords: Popular Science texts; Chemistry teaching tools; teacher formation.

Resumen: Esta investigación tuvo como objetivo investigar la comprensión de los profesores entrevistados sobre el uso de textos de divulgación científica en las clases de Química, así como para identificar si estos textos se utilizan en el aula y cómo se utilizan. El trabajo se justifica por la necesidad de formar alumnos con conocimientos científicos, capaz de mirar el mundo críticamente y provocar cambios con posiciones razonadas y responsables, basado en el hecho de que el dominio del conocimiento científico y la comprensión de la naturaleza de la ciencia son necesarios para comprender cómo implica el conocimiento científico en los distintos ámbitos de la sociedad. Para ello, se aplicaron cuestionarios y se realizaron entrevistas con profesores de Química que laboran en el sistema escolar público de la región Blumenau/SC, cuyas respuestas fueron categorizadas y sometidas a Análisis de Contenido. Se encontró que los textos están en el aula, pero no están ampliamente explorados, lo que indica la necesidad de complementar la formación de los docentes.

Palabras-clave: artículos de divulgación científica; instrumentos de enseñanza de la Química; formación de profesores.

\section{INTRODUÇÃO}

A Base Nacional Comum Curricular do Ensino Médio (BNCC) atribui às escolas o papel de contribuir na formação de jovens capazes de serem críticos e autônomos, no sentido de compreenderem as informações de fenômenos culturais e naturais para tomar decisões fundamentadas e responsáveis (BRASIL, 2018). Chassot (2016) explica que a alfabetização científica é um conjunto de conhecimentos que possibilita às pessoas uma leitura crítica do mundo e a compreensão da necessidade de transformá-lo para melhor. O autor também questiona o fato desta alfabetização ser restrita a quem está ligado diretamente com as Ciências, e salienta a necessidade desta barreira ser transposta.

Silva et al (2016) corroboram Chassot (2016) quando afirmam que a alfabetização cientifica é fundamental no processo educativo, pois é por meio dela que se forma o senso crítico. Delizoicov, Angotti e Pernambuco (2018) apontam que o acesso ao conhecimento científico deve ser promovido para que se estabeleça uma cultura científica, já que a Ciência é fruto da atividade humana e sócio-historicamente determinada. Para os autores, o conhecimento é uma interação não neutra entre sujeito (estudante) e objeto (conteúdo), e ao professor cabe a tarefa de planejar e mediar atividades que promovam interações adequadas.

Recebido em: $17 / 02 / 2021$

Aceite em: $31 / 08 / 2021$ 
A fim de propiciar interações adequadas e significativas, é importante trazer o mundo externo para o contexto escolar, através de "notícias de jornal, as novidades da internet, [...] visitar museus e exposições de divulgação científica, como parte da vida escolar.” (DELIZOICOV, ANGOTTI, PERNAMBUCO, 2018, p. 119). Ao ponderar sobre a necessidade de se educar um estudante com a cultura científica, crítico, com habilidades de argumentação, é fundamental pensar em pesquisas e propostas voltadas à disseminação de materiais de divulgação científica como instrumentos que possam auxiliar na formação integral do estudante. Além disso

[...] os processos de ensino-aprendizagem de ciências e divulgação científica se vêem cada vez mais justificados. Não no sentido de que tenhamos uma formação enciclopédica [...]. Mas, sim, de que estejamos formados em uma ideia contemporânea da ciência, pronta a se conceber capaz de mudanças e autoquestionamentos (LOPES, 1999, p. 108).

Nesse contexto, trabalhos como o de Ferreira e Queiroz (2012a) e Batistele (2016) sugerem o uso de textos de divulgação científica (TDC) como um instrumento de ensino em sala de aula para promover a incorporação do saber científico e o desenvolvimento de atitudes nos estudantes, como o hábito de leitura e a argumentação. A BNCC acentua que a seleção, produção, aplicação e avaliação de recursos didáticos e/ou tecnológicos adequados podem aprimorar o processo educativo. $\mathrm{Na}$ área de Ciências da Natureza e suas Tecnologias uma das habilidades envolve o desenvolvimento da capacidade de interpretação de TDC sobre temas de Ciências da Natureza "visando construir estratégias de seleção de fontes confiáveis de informações" (BRASIL, 2018, p. 559).

Em direção à formação integral, busca-se também romper com o cientificismo, com o positivismo e a visão da Ciência como neutra (BRASIL, 2018; DELIZOICOV, ANGOTTI e PERNAMBUCO, 2018; CHASSOT, 2016). Estas concepções sobre Ciência ainda estão presentes nas aulas do Ensino Médio, reflexo da formação inicial dos professores, que privilegia o aprendizado dos conteúdos específicos de maneira fragmentada e desconexa de discussões sobre seu significado e papel no contexto histórico (SILVA et al, 2016; DELIZOICOV, ANGOTTI e PERNAMBUCO, 2018).

Os TDC podem ser introduzidos em sala de aula com o objetivo de romper com essa visão clássica e acrítica da Ciência, ao propor textos que tratem da natureza da Ciência e das suas relações com a Tecnologia e Sociedade (BATISTELE, 2016). Gomes (2012) ainda aponta que os materiais de divulgação científica, seja na forma de texto ou

Recebido em: $17 / 02 / 2021$

Aceite em: $31 / 08 / 2021$ 
outros recursos, tornam o conhecimento mais significativo, têm um papel social quanto à formação, além de, em seu caráter informativo, ser um direito do cidadão.

É em direção à alfabetização científica, no sentido de formar um estudante crítico com competências e habilidades para leitura de mundo e ciente da natureza da Ciência que se propõe a presente pesquisa, com foco nos TDC como um instrumento de ensino. A escolha de TDC como instrumento de interesse de estudo é justificada pela facilidade de acesso, já que há revistas especializadas que disponibilizam textos online de maneira gratuita. Além disso, se todos os estudantes tiverem acesso ao texto, impresso ou online, não haverá a necessidade de usar artifícios audiovisuais para ser utilizado em sala de aula. Esta possibilidade amplia o uso de TDC, principalmente para escolas que não dispõem de recursos diferenciados (BATISTELE, 2016).

A ausência de experiências com TDC durante a formação inicial de professores de ciências pontuada por Nascimento e Rezende Júnior (2010) provocou a reflexão sobre as possíveis concepções dos professores atuantes no ensino de Química na rede pública da região de Blumenau sobre TDC, alinhado ao seu percurso formativo. Desta maneira, buscou-se conhecer se e como ocorre o uso de textos de divulgação científica em sala de aula e quais os motivos que levam os professores a utilizá-los ou não. Ademais, buscouse investigar o entendimento dos entrevistados sobre o uso de TDC nas aulas de Química como meio difusor de conhecimentos científicos, bem como apresentar os textos como uma alternativa de recurso didático.

Sendo assim, a presente pesquisa justificou-se na necessidade de formar sujeitos alfabetizados cientificamente, capazes de olhar o mundo criticamente e provocar-lhe mudanças com posicionamentos fundamentados e responsáveis, sendo o uso de TDC em sala de aula uma das alternativas para contribuir nesta formação. Nesta perspectiva, optou-se por abordar os professores em atuação, pois "não são textos feitos para a escola, portanto, é importante tomar conhecimento das apropriações feitas pelos professores sobre esse tipo de material, estejam em serviço ou em formação." (FERREIRA e QUEIROZ, 2012b, p. 44). Como os TDC não são feitos para o ambiente escolar, é importante esclarecer sua estrutura textual e sua finalidade, que serão discutidas a seguir. 


\section{DIVULGAÇÃO CIENTÍFICA}

A Divulgação Científica está atrelada à função de levar a informação produzida pela ciência ao público em geral, através de uma readequação da linguagem científica para uma linguagem não especializada (BUENO, 1985). Apesar de muito difundida pelos meios midiáticos, a divulgação científica não está restrita ao chamado jornalismo científico, mas inclui textos pontuais inseridos em livros didáticos, histórias em quadrinhos, folhetos educativos, materiais informáticos, documentários, programas especiais de rádio e televisão (BUENO, 1985).

É importante salientar que, atualmente, a grande difusão do uso das redes sociais tem promovido um novo meio de divulgação científica, por meio de publicações, vídeos, sites e podcasts, este último ganhando público no país nos últimos anos (MARQUES, 2019). Zamboni (1997) informa que a divulgação científica tem uma função educativa, além do caráter informativo, entretanto, Cunha e Giordan (2009) esclarecem que não cabe ao divulgador científico, ou seja, aquele que produz o material de divulgação, ensinar Ciências. O divulgador científico, que exerce o papel de comunicar ao público leigo, pode ser um cientista ou também jornalistas que contam ou não com a colaboração de especialistas (GOMES, 2012).

O discurso da divulgação científica é "constituído por elementos de esferas diferentes" (CUNHA; GIORDAN, 2009, p. 3), e entre discurso científico e discurso jornalístico, Zamboni (1997) defende que a divulgação científica é o resultado do trabalho da formulação de um novo discurso, e não apenas de uma reformulação textual. A necessidade do discurso de divulgação científica não ser apenas uma reformulação textual está atrelada à importância de "chamar a atenção do leitor, despertar-lhe interesse por determinado assunto ou tema, fazer com que ele se sinta envolvido pela questão e, principalmente que a questão tratada no texto tenha ligação com seu cotidiano" (CUNHA; GIORDAN, 2009, p. 6).

Nesse sentido, a escrita de um material de divulgação científica é estruturada em função do interlocutor, e dependendo deste, o discurso é mais aproximado ou não do discurso científico. A composição textual do material é o conhecimento científico transformado em informação, o que gera novas significações entre o discurso da ciência e de divulgação (CUNHA; GIORDAN, 2009). 
Sendo assim, entende-se divulgação científica como a produção de um recurso textual e/ou visual com o intuito de informar o interlocutor acerca de conteúdos científicos e tecnológicos, seus princípios e avanços. Essa produção é caracterizada por superar uma readequação do discurso científico, ao passo que é elaborada a partir da ressignificação deste discurso, utilizando uma linguagem adequada ao receptor do recurso.

\section{METODOLOGIA}

A partir de atividades realizadas em escolas ao longo das disciplinas de Prática como Componente Curricular e Estágio Supervisionado, do curso de Licenciatura em Química, essa pesquisa buscou investigar um conjunto de concepções e atitudes de um grupo de professores de Química, atuantes no Ensino Médio em escolas públicas de Blumenau/SC e região.

A pesquisa, de caráter qualitativo, ocorreu em duas etapas, sendo a primeira constituída pelo envio de um questionário eletrônico, estruturado conforme os princípios apresentados por Günther (2003) e Gil (2014). O objetivo foi verificar se os professores utilizam ou não os TDC em sala de aula e quais as características de sua aplicação. Ao finalizar o questionário, os professores sinalizaram sua disposição para participar da segunda etapa da pesquisa, na qual foram realizadas entrevistas semiestruturadas para investigar as práticas sobre o uso ou não dos TDC em sala de aula. $\mathrm{O}$ roteiro foi construído a partir dos pressupostos de Minayo e Costa (2018) e Gil (2014).

O contato inicial com os participantes foi através do envio de e-mails, para 29 escolas públicas de Blumenau e região. Não havendo retorno por este meio, fez-se contato telefônico com 10 escolas e seus representantes sugeriram que o contato deveria ser feito diretamente com o/a professor/a de Química, pessoalmente ou por outro meio. Como estes representantes não disponibilizaram nenhum telefone ou e-mail particular, o contato com os professores foi feito a partir de visitas às escolas. Os participantes da pesquisa foram os professores que se mostraram disponíveis para conceder entrevista após a visita. Desta forma, sete participantes responderam o questionário eletrônico e seis foram entrevistados. Todos os participantes atuam como professores de Química em escolas públicas de Blumenau e região, sendo cinco professores da rede estadual e dois da rede federal de ensino.

Recebido em: $17 / 02 / 2021$

Aceite em: $31 / 08 / 2021$ 
As respostas dadas pelos entrevistados foram analisadas a partir da perspectiva da Análise de Conteúdo, proposta por Bardin (2016). Foi realizada uma leitura flutuante das respostas, o que possibilitou uma visão de conjunto acerca do uso ou não de textos de divulgação científica nas aulas. A categorização elaborada está apresentada abaixo, na Figura 1.

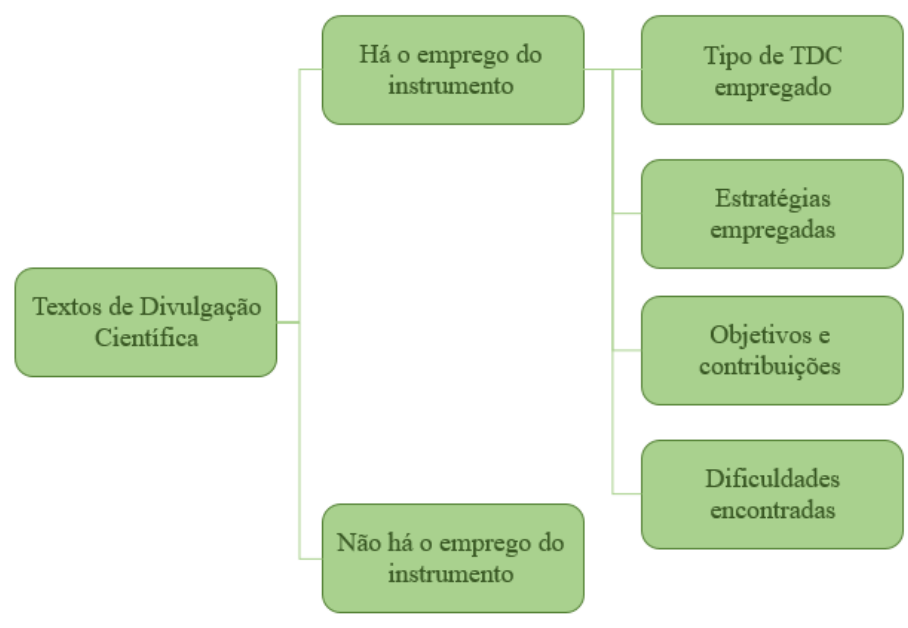

Fonte: As autoras, 2019.

Figura 1: Categorização estabelecida para análise das respostas.

A partir do uso ou não, foram elaboradas unidades de análise sobre a aplicação dos TDC, o que resultou na categorização dos dados, seguido de uma síntese interpretativa.

\section{PERFIL DOS PROFESSORES ENTREVISTADOS}

Tendo em vista que a presente pesquisa tem os educadores como os sujeitos da mesma, é importante buscar como o uso de TDC está presente na formação dos professores. Para compreender o processo formativo dos professores entrevistados, eles foram questionados sobre este processo. Para cada entrevistado(a), foram utilizados nomes fictícios: Eduardo, Leonardo, Isabel, Milena, Cristian e Júlio. Todos são licenciados em Química, sendo que Eduardo também é licenciado em Ciências e Isabel bacharel em Química.

Os entrevistados foram questionados sobre a presença de materiais de divulgação científica durante seu processo formativo. Dois professores afirmaram que não Recebido em: $17 / 02 / 2021$ 
recordavam se houve algum uso de TDC, já outros quatro mencionaram o uso de artigos científicos por professores do curso de graduação. O professor Eduardo mencionou que se recordava de textos que tratavam de meio ambiente e, quando realizou uma especialização na área de educação, um professor da disciplina de Filosofia da Educação utilizou TDC para promover discussões. Isabel não recordou as temáticas, mas mencionou que eram artigos que buscavam apresentar a aplicação do conteúdo específico.

Ainda na mesma perspectiva, os professores foram instigados a recordarem se a temática de divulgação científica foi abordada nas disciplinas de ensino. Três professores afirmaram que sim, mas que não eram discussões voltadas a como levar para a sala de aula, já o professor Júlio mencionou que teve contato com a metodologia de Gowin nestas disciplinas.

Gomes (2012) atribui à formação inicial de professores a responsabilidade de proporcionar aos licenciandos a experiência de trabalhar com TDC, pois "para que ele seja material educacional, precisa ser compreendido em sua essência pelo professor que irá utilizá-lo como estratégia didática" (GOMES, 2012, p. 120). A ausência de experiências com textos e outros materiais de divulgação científica pelos professores entrevistados durante seu processo formativo é um aspecto que auxilia a compreender o uso ou não destes materiais por estes professores, que será discutido em breve.

Além de proporcionar uma experiência ao licenciando daquilo que utilizará com seus estudantes no futuro (GOMES, 2012), há pesquisas sobre como TDC contribuem na formação inicial dos professores (CORREIA; SAUERWEIN, 2017; GOMES, 2012; FERREIRA; QUEIROZ，2012b; FERREIRA; IMASATO; QUEIROZ， 2011), especialmente quanto à autoria na produção de textos; sentidos atribuídos à leitura e interpretação de questões sobre TDC; discursos pedagógicos sobre temas presentes em TDC; análise de textos produzidos por licenciandos e predisposição ao uso após leituras de TDC (CORREIA; SAUERWEIN, 2017).

Gabana, Lunardi e Terrazzan (2003) alertam que a falta do hábito de leitura pelos professores também pode afetar o aproveitamento do uso de textos de divulgação científica em sala de aula. Nesse sentido, os professores foram questionados sobre seus hábitos de leitura e apenas um dos entrevistados afirmou não ter. Os demais relataram brevemente seus hábitos, por exemplo, Isabel e Leonardo costumam fazer leituras 
rápidas de conteúdos ligados à Ciência, geralmente notícias e artigos breves. Isabel deu ênfase ao hábito de ler artigos da área de Ensino de Química. Eduardo e Milena foram mais extensos em suas respostas, assim como são seus hábitos.

Além de procurar conteúdos em sites de notícias da área científica, Milena utiliza a leitura como um hobbie e costuma ler muitos livros de literatura variada, inclusive infanto-juvenil. Ela deixou claro que comenta com seus alunos sobre sua paixão pela leitura e tenta incentivá-los a lerem o que gostam, através de falas como: "se tu gosta de história, vai ler sobre". Ainda relatou que incentiva os estudantes a utilizarem a internet para leitura e pesquisa, buscando motivá-los a se apropriarem de conceitos científicos e pesquisar materiais auxiliares ao livro didático. Faz isso, inclusive, compartilhando links de leituras próprias para os estudantes, através de aplicativos de mensagens. Eduardo comentou que possui uma meta de leitura anual de 15 livros, sendo que três destes devem ser técnicos, como livros universitários de áreas específicas. Explicou que também consome conteúdos de revistas e sites, que costuma levar para sala apenas após sua leitura: "se eu levo para a sala é porque eu li".

Sobre a seleção do texto de divulgação científica, Cantanhede, Alexandrino e Queiroz (2015) detalham que o professor, ao fazer a leitura cuidadosa do material, busque todas as informações relevantes; relacione os conteúdos de Química formais e possibilidades de temas transversais (se este for o objetivo); busque equilíbrio com outra(s) estratégia(s); selecione textos contemporâneos e ligados ao cotidiano dos estudantes; analise o tamanho do texto e destine o tempo adequado para a(s) atividade(s); planeje a(s) aulas(s) com o recurso (tanto a estratégia quanto os conteúdos) e promova a leitura e discussão de maneira atenta para explorar todas as potencialidades do texto e para que os estudantes compartilhem suas contribuições.

A importância de se conhecer o texto que utiliza em sala de aula é destacada por Gomes (2012), além de outros aspectos, como a necessidade do planejamento da aula com TDC, com objetivos definidos, meios de enfoque, métodos avaliativos; critérios de seleção de um texto e suas opções de trabalho com o material. Esta autora ressalta estes pontos para esclarecer a importância de apresentar esse tipo de material já na formação inicial de professores. A esse respeito, Colpo (2019) relatou que os TDC estiveram presentes ao longo do curso de graduação e contribuíram para sua formação, principalmente pela especificidade da linguagem dos TDC e das potencialidades em 
mediar estratégias de leitura em sala de aula. Em outro trabalho, Zismann, Bach e Wenzel (2019) constataram que a atividade de leitura de um TDC realizada com estudantes do segundo ano do Ensino Médio, favoreceu a contextualização e a compreensão dos conteúdos de cinética Química relacionados no texto. Além de constituir uma forma de qualificar os sentidos que os estudantes atribuem à Química, os autores ressaltaram "a importância de uma prática de leitura orientada, conduzida por meio de estratégias de leitura, como o uso de perguntas, ou de escritas relacionadas à leitura" (ZISMANN; BACH; WENZEL, 2019, p135).

Assim como Chassot (2016), Delizoicov, Angotti e Pernambuco (2018) afirmam que o docente que ensina Ciências deve promover o acesso ao conhecimento científico e tecnológico aos estudantes, bem como uma apropriação do conhecimento de maneira crítica, a fim de prover a formação cidadã e o pensamento crítico, propostos pela BNCC (BRASIL, 2018). Nesse sentido, os professores foram questionados sobre o objetivo de ensinar Química para os estudantes, segundo suas convicções próprias. Quatro professores mencionaram a importância de relacionar o conteúdo com o cotidiano do estudante, mostrando a proximidade da Ciência com o dia-a-dia da sociedade, e a partir desta aproximação, abordar outras questões da formação do estudante. Por exemplo, Milena comentou sobre a importância de discutir a natureza da Ciência para mostrar que não é limitada ao laboratório e que o conhecimento científico é construído constantemente. Isabel mencionou a alfabetização científica como objetivo relacionado a aproximar conteúdo e cotidiano. O professor Júlio atribui o Ensino de Química à formação de um sujeito autônomo, e explicou que busca que seus estudantes se apropriem do conhecimento para serem críticos em relação ao mundo: "eu falo para eles que acordar cedo pra estar aqui [na aula] tem que ter um motivo, e esse motivo é ter autonomia". A partir da próxima sessão serão apresentadas as categorias de análise relacionadas à aplicação de TDC em sala de aula.

\section{CARACTERÍSTICAS DA APLICAÇÃO DE TEXTOS DE DIVULGAÇÃO CIENTÍFICA EM SALA DE AULA}

Batistele (2016) propôs uma análise de textos publicados na revista Minas Faz Ciência, para averiguar seus potenciais usos como textos de divulgação científica. Para 
isso, dedicou um capítulo de sua dissertação para elencar as características encontradas em publicações que reportam o uso de TDC em sala de aula. Em seu trabalho, salienta que o uso de textos de divulgação científica em sala de aula é apontado como um instrumento de ensino que "possibilita levar o aluno a se posicionar criticamente em relação a conceitos científicos” (BATISTELE, 2016, p. 20). Destaca, ainda, que essa abordagem promove o desenvolvimento de habilidades de leitura, além de contribuir com a interdisciplinaridade e a cidadania enquanto provedoras das relações entre Ciência, Tecnologia e Sociedade, corroborando a educação para a vida.

A partir das respostas dadas pelos professores que afirmaram utilizar TDC em sala de aula, foram estabelecidas categorias para a análise das respostas. A primeira categoria está relacionada ao tipo de texto de divulgação científica empregado em sala de aula, cuja frequência de respostas está apresentada na Figura 2.
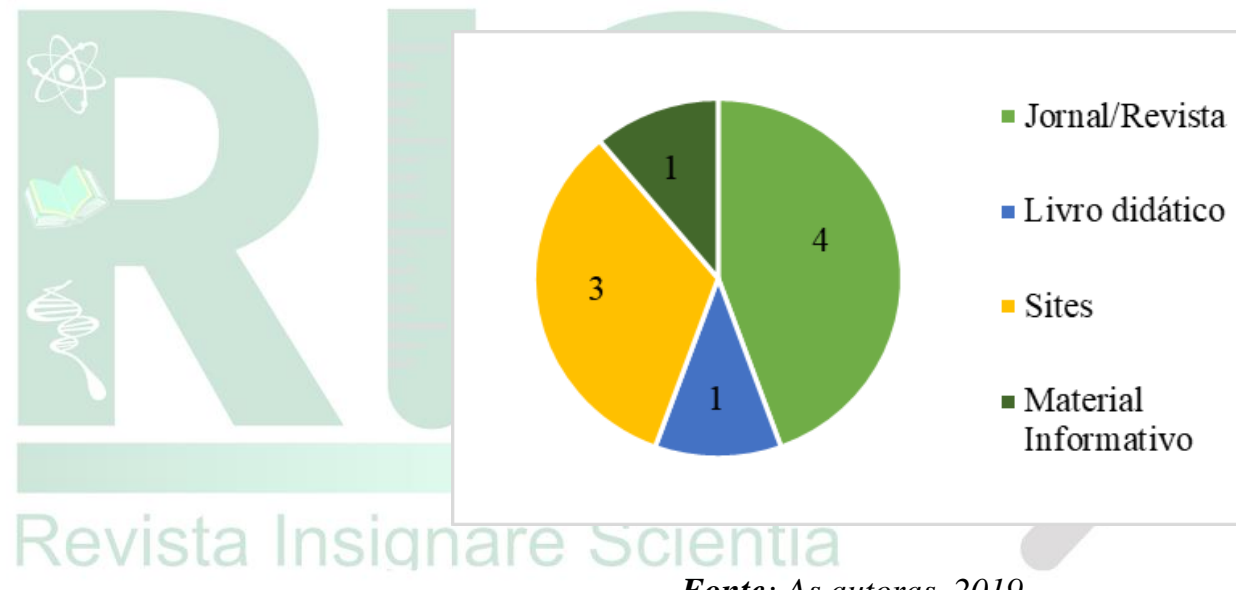

Fonte: As autoras, 2019.

Figura 2: Frequência de resposta para qual tipo de TDC utilizado em sala de aula.

Durante a entrevista, Isabel e Eduardo ainda apontaram que utilizam rótulos de alimentos para discutir e promover a aprendizagem da linguagem científica. Os rótulos de alimentos não são caracterizados como textos de divulgação científica, pois são informações que não passaram por uma nova formulação de discurso em função do interlocutor, como descreve Zamboni (1997) e Cunha e Giordan (2009). A menção aos rótulos como um TDC pelos professores mostra um equívoco sobre o que são esses textos e o que pode ser trabalhado a partir deles. Um dos professores citou ter usado textos de livros didáticos de nível universitário, mas não explicou como foi a experiência. Batistele (2016) aponta que os textos de revistas são os mais empregados, pois possuem características que facilitam o uso em sala de aula, como tamanho, visual 
e linguagem simples. Apesar de não terem sido questionados sobre a escolha desses materiais, as respostas dos professores corroboraram o estudo de Batistele (2016).

A segunda categoria tem o intuito de discorrer sobre as motivações que levaram os professores a utilizarem TDC e os resultados encontrados após o uso em sala de aula. Em revisões de publicações acerca do uso de textos de divulgação científica, Ferreira e Queiroz (2012a) e Batistele (2016), indicaram que os principais objetivos do emprego de materiais de divulgação científica apresentados nos trabalhos estudados foram: favorecer a aprendizagem de conceitos; desenvolver e fomentar habilidades de leitura, interpretação, discussão e argumentação; despertar curiosidade e interesse e discutir aspectos da ciência/produção do conhecimento científico.

No questionário, os professores apontaram quais objetivos, entre os apresentados por Batistele (2016), os motivaram a utilizar TDC. Em seguida, foram questionados sobre quais desses objetivos foram alcançados após o uso de TDC em sala de aula. As respostas estão sintetizadas no quadro 3.

Quadro 1: Segunda categoria de análise: motivações e resultados do emprego de textos de divulgação científica em sala de aula, apresentados como frequência de respostas dadas.

\begin{tabular}{|c|c|c|}
\cline { 2 - 3 } \multicolumn{1}{|c|}{} & $\begin{array}{c}\text { Objetivo ao } \\
\text { planejar o uso do } \\
\text { TDC }\end{array}$ & $\begin{array}{c}\text { Objetivo } \\
\text { alcançado após } \\
\text { uso de TDC }\end{array}$ \\
\hline Despertar interesse e curiosidade & 5 & 4 \\
\hline Favorecer a aprendizagem de conceitos & 3 & 3 \\
\hline $\begin{array}{c}\text { Discussão aspectos da Ciência/produção do } \\
\text { conhecimento científico }\end{array}$ & 2 & 2 \\
\hline $\begin{array}{c}\text { Desenvolver/fomentar habilidades de leitura e } \\
\text { interpretação }\end{array}$ & 3 & 2 \\
\hline $\begin{array}{c}\text { Desenvolver/fomentar habilidades de } \\
\text { argumentação e discussão }\end{array}$ & 4 & 3 \\
\hline
\end{tabular}

Fonte: As autoras, 2019.

Entre os quatro professores entrevistados que utilizam TDC em sala, três relacionaram o propósito de usar um TDC para despertar interesse e curiosidade no estudante, ou seja, como uma forma de diferenciar a aula. Eduardo relacionou despertar interesse com "sair da mesmice dos conteúdos."; já Milena enfatizou que o livro didático é "sem sal" para que os estudantes se mantenham interessados. Desta forma, os professores relataram que usam os textos para buscar o interesse dos estudantes através Recebido em: $17 / 02 / 2021$

Aceite em: $31 / 08 / 2021$ 
de aulas diferenciadas, mantendo uma aproximação entre conteúdo escolar e cotidiano do estudante pela escolha dos textos trabalhados.

Entre os objetivos alcançados, os professores entrevistados elencaram que algumas habilidades são desenvolvidas. Isabel salientou que os estudantes desenvolvem a habilidade de destacar informações relevantes e, dessa forma, conseguem sintetizá-las de forma coerente. Milena enfatizou que observa contribuições ao discutir como a Ciência está em constante construção, pois assim o estudante enxerga o mundo científico mais próximo de seu cotidiano, ao interpretar notícias sobre avanços das diferentes áreas da Ciência. Eduardo ressaltou que o comportamento da turma é modificado durante uma atividade com TDC.

A terceira categoria teve como foco conhecer as estratégias empregadas pelos professores para trabalhar os textos em sala de aula. A frequência de respostas é apresentada na Figura 3.

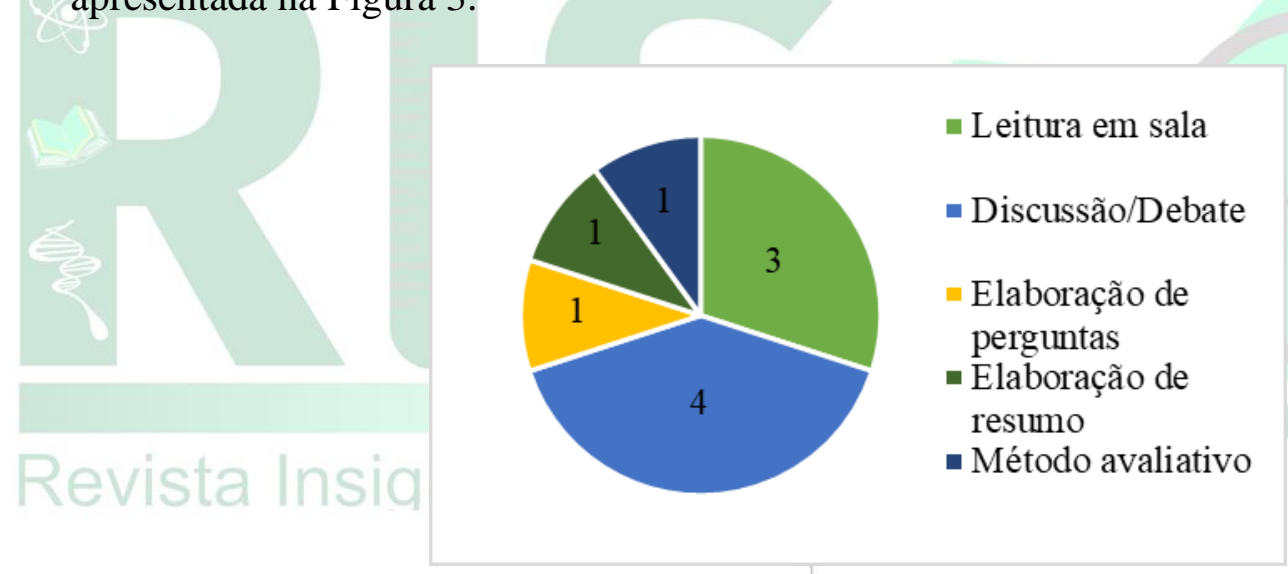

Fonte: As autoras, 2019.

Figura 3: Frequência de respostas para a estratégia de trabalho de TDC em sala de aula.

Nas entrevistas, os professores detalharam as estratégias que usam em suas aulas. Isabel explicou que promove leituras, individuais e/ou coletivas, e em seguida faz uma discussão ou pede aos estudantes para responderem um questionário. Eduardo desenvolve a leitura e utiliza o texto como método avaliativo através de resumos ou avaliações tradicionais, mas salientou que mantém o TDC como material passível de consulta. Milena comentou que prefere pequenos e informais debates, pois costuma disponibilizar links através de mensagens ou alimenta seu blog com textos: "às vezes eu tô ali na aula e pergunto: vocês leram?". 
Milena também relatou que possuía o hábito de utilizar os textos como material de apoio para promover debates estruturados, em práticas como o Júri Simulado. Explicou que fornecia previamente TDC para os grupos e que a partir deles os estudantes deveriam construir seus argumentos para o debate. Ela mencionou que as atividades ocorriam de maneira muito construtiva, com diversas habilidades dos estudantes sendo desenvolvidas, mas que nas últimas vezes não obteve os resultados esperados e optou por deixar de adotar essa prática.

As estratégias relatadas pelos professores participantes da pesquisa são coerentes com as apresentadas pelos autores de publicações sobre uso de textos de divulgação científica em sala de aula. Esses trabalhos apresentam exemplos de estratégias, como a leitura dos textos, aplicação de questionários; realização de discussões e debates; elaboração de textos e perguntas pelos estudantes; leitura para a resolução de problemas investigativos (FERREIRA; QUEIROZ, 2012a; BATISTELE, 2016).

É importante destacar que, apesar do texto de divulgação científica ser elaborado com o intuito de levar conhecimentos científicos ao interlocutor leigo, em situação de ensino o uso do TDC não garante que o estudante assimile o conhecimento científico, sendo necessário o conhecimento do professor sobre o texto (FERREIRA; QUEIROZ, 2012a). Gomes (2012) apresenta os TDC como mediadores no processo de ensino e aprendizagem e o professor assume o papel de apresentar o texto e conduzir sua utilização, sendo também um mediador que tem seu planejamento orientado pelas motivações e intenções do uso do material. Nos relatos dos professores entrevistados, não ficou claro como apresentam os TDC e mediam as leituras e/ou os debates propostos.

A quarta categoria está relacionada às dificuldades encontradas pelos professores ao utilizar os textos de divulgação científica em sala de aula. Batistele (2016, p. 40) elencou as dificuldades encontradas pelos autores dos trabalhos analisados em sua pesquisa sobre "o uso de TDC em atividades didáticas em sala de aula da educação básica," que foram apontadas como dificuldades de leitura e interpretação dos estudantes; incompreensão de termos científicos específicos e, no caso de um dos artigos analisados, pouco tempo para a aplicação das atividades.

Quatro entre cinco professores participantes dessa pesquisa corroboraram o levantamento de Batistele (2016), ao assinalarem que a dificuldade de compreensão de Recebido em: $17 / 02 / 2021$ 
termos científicos é um dos obstáculos. Além disso, a dificuldade de leitura e interpretação por parte dos estudantes foi apontada três vezes no questionário aplicado aos participantes. Essa dificuldade de leitura e interpretação está relacionada aos hábitos de leitura dos estudantes, mas Ferreira e Queiroz (2012a) pontuam que a falta deste hábito pelos estudantes não deve ser considerada um desmotivador para o emprego dos textos em sala, mas sim um indicador da urgência de trabalhar com TDC.

O tempo para execução das atividades foi apontado duas vezes como um percalço. $\mathrm{Na}$ entrevista, as professoras Isabel e Milena destacaram que os perfis de turma podem impactar na atividade. Milena enfatizou que despertar a curiosidade dos estudantes é uma das dificuldades e Isabel afirmou que às vezes é difícil conseguir atenção da turma toda para a realização da atividade, além de que: "dependendo da turma, utilizar um texto é maçante para eles".

O professor Júlio apresentou duas perspectivas de resposta. Ele atua em dois níveis de ensino na mesma escola, que são o Ensino Médio regular e o profissionalizante que forma técnicos em Química e pontuou que costuma utilizar artigos científicos e demais TDC apenas no curso técnico. Júlio apontou que os estudantes de nível técnico utilizam os textos para embasar trabalhos a serem apresentados e avaliados. Para ele, o estudo do texto proporciona aos estudantes a melhora em habilidades de interpretação e a estratégia de apresentação contribui para o desenvolvimento da oralidade. Ao ser questionado porque não utiliza os textos com o Ensino Médio regular, o professor repensou sua própria prática: “boa pergunta... não sei. Na verdade, assim, eu já tenho todo o material já preparado, todos os slides do conteúdo... então a gente opta pela praticidade né, mas posso pensar em utilizar".

Frente à abertura ao uso de TDC nas turmas regulares de Ensino Médio, o professor foi instigado a refletir se encontraria alguma dificuldade em trabalhar algum TDC com os estudantes. Em resposta, afirmou que acredita que não haveria grandes dificuldades: "até porque esses textos de notícia, por exemplo, tem linguagens mais fáceis, menos técnicas".

Nem todos os professores participantes utilizam TDC em sala de aula. Para discutir as motivações, foi estabelecida uma nova categoria, que será apresentada na sessão seguinte. 


\section{DOS PROFESSORES QUE NÃO UTILIZAM TDC EM SALA DE AULA}

Dois professores afirmaram que não fazem uso deste instrumento de ensino. As justificativas foram distintas para cada professor. Leonardo atribuiu a ausência de experiências com TDC durante sua formação como um motivo: "eu não conheço $a$ prática... nunca trabalhei isso durante minha formação, nem nas continuadas". Cristian explicou que costuma seguir o livro didático, não variando muito suas aulas com outros recursos, apesar de utilizar vídeos e incentivar pesquisas breves na internet.

Com o intuito de promover o uso de TDC, a pergunta seguinte foi: "Vários autores indicam que o uso de TDC em sala de aula contribui na formação do estudante ao promover a aprendizagem conhecimento científico, além de desenvolver hábitos de leitura e interpretação, argumentação, melhora a interação entre os estudantes. A partir disso, você teria interesse de utilizar TDC em suas aulas?”. Ambos afirmaram que teriam interesse em utilizar, porém Cristian já apontou uma dificuldade: "Utilizaria se eu desse aula em algum nível mais avançado. Há interesse em utilizar, mas no ensino público, o professor se sente menos motivado porque os alunos não tem interesse".

Leonardo admitiu que para utilizar, precisaria ter algum tipo de contato com o instrumento, seja por meio de publicações relatando o emprego de TDC ou por meio de exposições em formações continuadas. A fala desse professor vai ao encontro da ênfase dada por Gomes (2012) sobre a importância dos TDC na formação inicial, pelo potencial de se apresentarem para os futuros professores como uma nova estratégia de ensino que pode contribuir para a contextualização dos conteúdos de Química, a abordagem da natureza e história da Ciência, a experimentação e, também, aspectos do enfoque educacional Ciência, Tecnologia e Sociedade (CTS).

Nessa perspectiva, Ferreira e Queiroz (2012b) alertam que TDC podem ser utilizados com diferentes intenções e objetivos, trazer diferentes resultados conforme a atividade escolhida, além de depender do contexto das interações e a história de vida dos estudantes, o que reforça a necessidade de sua discussão durante o processo formativo.

\section{CONSIDERAÇÕES FINAIS}

Recebido em: 17/02/2021

Aceite em: $31 / 08 / 2021$ 
Discorrer, em sala de aula, sobre a natureza da Ciência tem sua importância assinalada por Lopes (1999), que explica sobre como a visão da Ciência como empirista, não ideológica, detentora da verdade, e sua linguagem não compreendida pelo público leigo a torna um meio de legitimar discursos deturpados ou não necessariamente científicos. Esta autora também destaca que a Ciência deve ser compreendida como um conjunto de ideias provisórias e relativas. Consideramos que o uso dos TDC em sala de aula pode auxiliar na desconstrução dessa visão de Ciência, na medida que são utilizados os formatos de notícias atuais relacionadas ao mundo científico, como apontou a professora Milena em suas experiências.

A apropriação do conhecimento científico e a compreensão da natureza da Ciência são fundamentais para os estudantes compreenderem como os conhecimentos científicos interferem nas diversas esferas da sociedade, a fim de levar o cidadão ser capaz de assumir posicionamentos favoráveis e/ou contrários. Os TDC podem ser utilizados como meio para relacionar os conceitos científicos específicos e suas conexões com a sociedade, e os professores entrevistados afirmaram que utilizam esse instrumento, buscam fazer essa interpelação com os estudantes.

Os professores relataram a ausência de experiência com os TDC durante sua formação inicial e continuada. A falta da vivência com textos no processo formativo reflete nas concepções sobre o que é um texto de divulgação científica, quais são suas possíveis contribuições e suas estratégias de utilização. Essa carência foi relatada nas práticas encontradas e não encontradas no decorrer das entrevistas, como explicitado pelos dois professores que não utilizam TDC em suas aulas.

Nos relatos sobre o uso dos textos em sala de aula, há uma limitação dos objetivos do emprego do instrumento frente às possibilidades apresentadas pela literatura, além da dificuldade e/ou ausência da mediação pelos professores entre estudante e texto. A mediação é fundamental para que o texto seja compreendido e discutido conforme os objetivos estabelecidos, pois o TDC tem função de divulgação em sua essência e passa a ser um instrumento de ensino a partir da ação de um professor sobre ele.

O contato com as contribuições que os textos podem proporcionar fez os professores repensarem suas práticas, ao ter uma abertura para o uso dos textos, bem como reforçou a continuidade do uso pelos professores que já utilizavam. Entretanto, assim como assinalou o professor Leonardo, é preciso que se tenha contato com o 
instrumento em algum nível formativo, para que se compreenda sua construção, seus objetivos de aplicação, as estratégias e suas contribuições. Todos os seis professores participantes corroboraram essa posição, afirmando ter interesse em momentos formativos que abordassem os TDC.

O posicionamento favorável ao uso dos textos em sala de aula se mostrou independente do ano ou local de formação dos professores. Apesar dessa pesquisa contar com apenas seis participantes, não foi possível observar a influência destes aspectos em suas práticas, diferente do que se observou em relação ao contato com esses textos durante o percurso formativo.

Dessa forma, entre os professores entrevistados, é possível identificar que os textos estão em sala de aula, porém não com todas as estratégias e contribuições exploradas, assinalando a necessidade de apresentar a esses professores os TDC, bem como outros instrumentos de ensino que não foram abordados em suas formações. Esse complemento à formação dos docentes, alinhada com outras características que condicionam a prática docente (estrutura da escola, a carga horária de aulas e carga horária de planejamento), amplia a visão e aplicação de metodologias de ensino com diferentes recursos didáticos com o intuito de promover uma aprendizagem menos fragmentada dos conhecimentos científicos. Proporcionar aos estudantes uma formação que dá sentido aos conhecimentos apresentados em sala contribui na construção de uma visão de mundo crítica, inclusive passível de mudança.

\section{REFERÊNCIAS}

BARDIN, Lawrence. Análise de Conteúdo. 1 ed (3 reimp). São Paulo: Edições 70, 2016. Tradução: Luis Antero Reto, Augusto Pinheiro.

\section{BATISTELE, Márcio C. B. Análise de Características de Textos de Divulgação}

Científica da Revista Minas Faz Ciência: possibilidades para o ensino de química. Dissertação (Mestre em Ensino de Ciências). Universidade Federal de Itajubá. Set. 2016. Disponível em https://repositorio.unifei.edu.br/xmlui/bitstream/handle/123456789/605/dissertacao_bati stele_2016.pdf?sequence=1\&isAllowed=y. Acesso em 20 jan. 2021.

BRASIL. Ministério da Educação. Base Nacional Comum Curricular. Brasília: MEC, 2018. Disponível em:

http://basenacionalcomum.mec.gov.br/images/BNCC_EI_EF_110518_versaofinal_site. pdf. Acesso em 20 jan. 2021.

Recebido em: $17 / 02 / 2021$

Aceite em: $31 / 08 / 2021$ 
BUENO, Wilson C. Jornalismo Científico: conceitos e funções. Ciência e Cultura (SBPC), n. 37, v. 9, p. 1420-1427, set. 1985.

CANTANHEDE, Severina C. S.; ALEXANDRINO, Daniela M.; QUEIROZ, Salete L. Textos de Divulgação Científica como Recurso Didático no Ensino de Química [recurso eletrônico]. Grupo de Pesquisa em Ensino de Química. IQSC. São Carlos, 2015. Disponível em http://www.gpeqsc.com.br/sobre/manuais/DivulgacaoCiencRecursoDidEnsiQuimica.pd f. Acesso em 20 jan. 2021.

CHASSOT, Áttico. Alfabetização Científica: questões e desafios para a educação. 7 ed. 344 p. Ijuí: Editora Unijuí, 2016.

COLPO, Camila C. Estratégias de leitura de Textos de Divulgação Científica e a constituição docente de uma Professora de Química. Revista Insignare Scientia, v.2, n.3 - Edição Especial: Ciclos formativos em Ensino de Ciências. 2019, p.48-55.

Disponível em https://periodicos.uffs.edu.br/index.php/RIS/article/view/11180/7249. Acesso em 20 jan. 2021.

CORREIA, Daniele; SAUERWEIN, Inés P. S. As Leituras de Textos de Divulgação Científica Feitas por Licenciandas no Estágio Supervisionado em Física. Revista Brasileira de Ensino de Física. n. 3, v. 36. 2017. Disponível em http://www.scielo.br/pdf/rbef/v39n3/1806-1117-rbef-39-03-e3401.pdf. Acesso em 20 jan. 2021.

CUNHA, Marcia B.; GIORDAN, Marcelo A Divulgação Científica como um Gênero de Discurso: Implicações na Sala de Aula. VII Encontro Nacional de Pesquisa em Educação em Ciências. 11 p. Florianópolis, 8 nov. 2009. Disponível em http://axpfep1.if.usp.br/ profis/arquivos/viienpec/VII\%20ENPEC\%20$\% 202009 /$ www.foco.fae.ufmg.br/cd/pdfs/89.pdf. Acesso em 20 jan. 2021.

DELIZOICOV, Demétrio; ANGOTTI, José. A. P.; PERNAMBUCO, Marta M. Ensino de Ciências: fundamentos e métodos. 5 ed. São Paulo: Cortez, 2018.

FERREIRA, Luciana N. A.; QUEIROZ, Salete L. Textos de Divulgação Científica no Ensino de Ciências: uma revisão. Alexandria: Revista de Educação em Ciência e Tecnologia, v.5, n.1, p. 3-31, maio 2012a. Disponível em https://periodicos.ufsc.br/index.php/alexandria/article/view/37695. Acesso em 20 jan. 2021.

FERREIRA, Luciana N. A.; QUEIROZ, Salete L. Textos de Divulgação Científica na Formação Inicial de Professores de Química. Alexandria: Revista de Educação em Ciência e Tecnologia, v.5, n.2, p. 43-67, set 2012b. Disponível em https://periodicos.ufsc.br/index.php/alexandria/article/view/37713. 20 jan. 2021.

FERREIRA, Luciana N. A.; IMASATO, Hidetake; QUEIROZ, Salete L. Textos de Divulgação Científica no Ensino Superior de Química: Aplicação em uma Disciplina de Química Estrutural. Educación Química. n. 23, v. 1. Universidade Nacional Autônoma

Recebido em: 17/02/2021

Aceite em: $31 / 08 / 2021$ 
do México, 2011. p 49-54. Disponível em

http://www.scielo.org.mx/pdf/eq/v23n1/v23n1a9.pdf. Acesso em 20 jan. 2021.

GABANA, Marciela; LUNARDI, Graziela; TERRAZZAN, Eduardo A. Textos de Divulgação Científica: Avaliando uma Estratégia Didática para o Ensino Médio. IV Encontro Nacional de Pesquisa em Educação em Ciências. Bauru, 2003. Disponível em http://abrapecnet.org.br/enpec/iv-enpec/painel/PNL234.pdf. Acesso em 20 jan. 2021.

GIL, Antônio C. Métodos e Técnicas de Pesquisa Social. 6 ed. São Paulo: Atlas, 2014.

GOMES, Verenna B. Divulgação Científica na Formação Inicial de Professores de Química. 2012. Dissertação (Mestre em Ensino de Ciências: Ensino de Química). Universidade de Brasília. Brasília, 2012. Disponível em http://repositorio.unb.br/bitstream/10482/12030/1/2012_VerennaBarbosaGomes.pdf. Acesso em 20 jan. 2021.

GUNTHER, Hartmut. Como elaborar um Questionário. Planejamento de Pesquisa nas Ciências Sociais. n. 1. Laboratório de Psicologia Ambiental. Brasília: UnB, 2003. LOPES, Alice R. C. Conhecimento Escolar: Ciência e Cotidiano. Rio de Janeiro: EdUERJ, p. 236, 1999.

MARQUES, Fabrício. Microfones Abertos para s Ciência. Revista Pesquisa FAPESP, ed. 277, p. 36-40, mar. 2019. Disponível em

https://revistapesquisa.fapesp.br/2019/03/14/microfones-abertos-para-a-ciencia/. Acesso em 20 jan. 2021.

MINAYO, Maria C. S.; COSTA, António P. Fundamentos Teóricos das Técnicas de Investigação Qualitativa. Revista Lusófona de Educação, n. 40. 2018. p. 139-153.

Disponível em

https://www.researchgate.net/publication/328403919_Fundamentos_Teoricos_das_Tec nicas_de_Investigacao_Qualitativa/link/5bcaf369458515f7d9cbf917/download. Acesso em 20 jan. 2021.

NASCIMENTO, Tatiana G.; REZENDE JUNIOR, Mikael. F. A produção de divulgação científica na área de educação em ciência: referenciais teóricos e principais temáticas. Investigação em Ensino de Ciências, v.15, n.1, p.97-120, 2010. Disponível em https://www.if.ufrgs.br/cref/ojs/index.php/ienci/article/view/317. Acesso em 20 jan. 2021.

SILVA, Patrícia F.; OLIVEIRA, Rénally M. A.; SILVA; Thiago P.; SILVA; Gilberlândio N.; FILHO, Francisco F. D. Alfabetização Científica na Visão dos Professores de Química de Escolas Públicas do Ensino Médio no Estado da Paraíba. XVIII Encontro Nacional de Ensino de Química. 10 p. Florianópolis, 2016. Disponível em http://www.eneq2016.ufsc.br/anais/resumos/R0139-2.pdf. Acesso em 20 jan. 2021.

ZAMBONI, Lilian M. S. Heterogeneidade e Subjetividade no Discurso da

Divulgação Científica. 1997. Tese (Doutorado em Linguística) - Instituto de Estudos

Recebido em: 17/02/2021

Aceite em: $31 / 08 / 2021$ 
da Linguagem. Universidade Estadual de Campinas. Campinas, 1997. Disponível em http://www.fiocruz.br/brasiliana/media/ZamboniLilianMarciaSimoesTese.pdf. Acesso em 20 jan. 2021.

ZISMANN, Jonatan J.; BACH, Sabrina T.; WENZWL, Judite S. A leitura de texto de divulgação científica no ensino de cinética química. Revista Insignare Scientia, v.2, n.1, jan./abr. 2019. Disponível em:

https://periodicos.uffs.edu.br/index.php/RIS/article/view/10802/7147. Acesso em 20 jan. 2021.

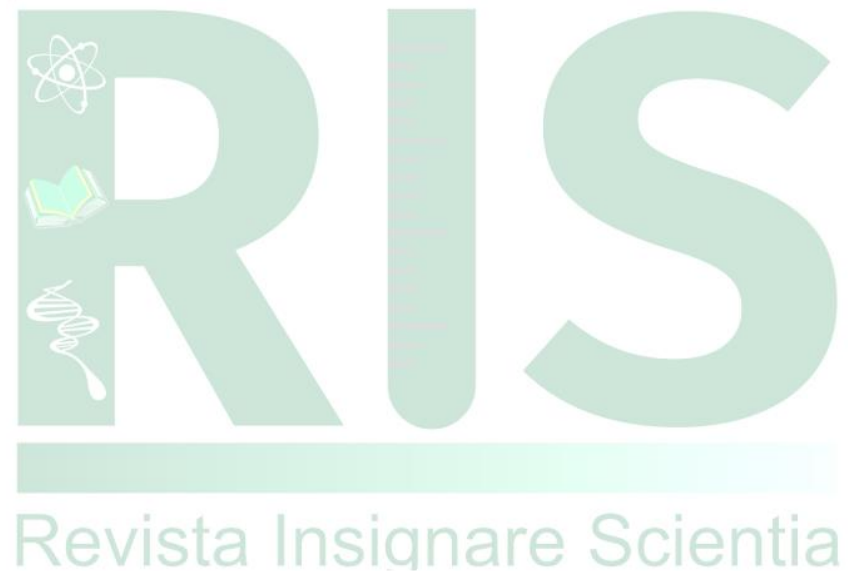

Recebido em: 17/02/2021

Aceite em: $31 / 08 / 2021$ 